\title{
Linking phenotypic correlations from a diverse set of laboratory tests to field behaviors in the crayfish, Orconectes virilis
}

\author{
David D. Edwards $^{1,2}$ | Kathryn E. Rapin ${ }^{1,2}$ | Paul A. Moore ${ }^{1,2}$ (D)
}

\author{
${ }^{1}$ Department of Biological Sciences, \\ Laboratory for Sensory Ecology, Bowling \\ Green State University, Bowling Green, $\mathrm{OH}$, \\ USA \\ ${ }^{2}$ University of Michigan Biological Station, \\ Pellston, MI, USA

\section{Correspondence} \\ Paul A. Moore, Department of Biological \\ Sciences, Bowling Green State University, \\ Bowling Green, OH, USA. \\ Email: pmoore@bgsu.edu \\ Editor: E. Hebets
}

\begin{abstract}
The presence of phenotypic behavioral correlations and their connection to fitness consequences of organisms have received considerable debate within the literature. Yet, little work has been carried out to connect any behavioral correlates found within a set of laboratory studies to natural behavior observed under complex environmental conditions. To help fill this gap, individual crayfish, collected from the same local population, completed five different behavioral assays in a laboratory setting in a random order. These data were used to reveal any possible correlations for behavioral scores across all of the laboratory tests. Subsequently, these same individuals were placed into the field and video recorded for $24 \mathrm{hr}$. A separate set of field behaviors, related to the laboratory assays, were quantified from the field videos. The normalized laboratory and field behaviors were used in three stepwise statistical analyses. First, normalized data were loaded into a PCA to generate a priori hypotheses on potential behavioral correlates. These hypotheses were subsequently tested using general multiple linear regression. Finally, structural equation modeling was performed to elucidate any behavioral modules from the laboratory assays that correlated with behavioral patterns present from the fieldwork. Three laboratory-based behavioral modules were connected to three separate field assays: explorationavoidance, bold-shy, and aggressiveness. Yet, some behaviors exhibited in the laboratory assays were uncorrelated with any behaviors found in the field and vice versa. Results from this study provide evidence that although many different behavioral correlates may exist within laboratory settings, these same modules may not translate directly into predicting behavior under natural settings.
\end{abstract}

\section{KEYWORDS}

behavioral phenotypes, crayfish, field behavior, structural equation modeling

\section{1 | INTRODUCTION}

Animals exhibit a wide suite of behaviors that vary depending on the context, but are also correlated between contexts (Gosling, 2001; Réale, Gallant, Leblanc, \& Festa-Bianchet, 2000; Sih, Bell, \& Johnson, 2004a, 2004b; Wilson, Clark, Coleman, \& Dearstyne, 1994). Within a population, individuals often exhibit a range of behaviors along a continuum. For example, on a boldness continuum, certain individuals will be consistently bolder or shyer than others. However, the behavior exhibited by individuals varies across contexts, creating an individual-derived continuum of behavior nested within the overall consistent population distribution along a behavioral continuum 
(Dall, Houston, \& McNamara, 2004; Sih, Bell \& Johnson, 2004a). These individually plastic behaviors can be termed contextual plasticities because the exact behavioral phenotypic display is dependent upon the context (Stamps, 2016). Domesticated rainbow trout take more risks when foraging relative to native fish that are subject to higher predation within their habitats (Wilson \& Stevens, 2005). This increased level of risk demonstrated by the domesticated fish led to increased foraging and body size, which was beneficial for those organisms from a fitness standpoint. Conversely, when placed in habitats with similar predation risks, domesticated fish continued to take more risks than the natives, increasing their level of mortality (Biro, Abrahams, Post, \& Parkinson, 2004). Even though changing the context (e.g., habitat with low or high predation risk) may allow for a shift in risk-taking behavior or "riskiness" for some individuals, these same animals are still "riskier" individuals than the average population response. In those situations where a single animal displays a consistent pattern of behavior across different tasks (i.e., stays within a certain range on the population continuum), the pattern of consistency within the individual animal has been termed a behavioral syndrome (Sih, Bell \& Johnson, 2004a, 2004b).

Although contextual plasticity is usually measured along a variation in a single variable, the contextual complexity of natural environments would dictate a multidimensional plasticity (Dosmann \& Mateo, 2014; Westneat, Hatch, Wetzel, \& Ensminger, 2011; Westneat, Wright, \& Dingemanse, 2015). In the guppy (Poecilia reticulata), females prefer males who exhibit behaviors denoting bold individuals such as those willing to approach predators (Godin \& Dugatkin, 1996). Mosquito fish that are on the higher end of the sociability continuum (i.e., are more social) disperse farther distances than less social fish, allowing them to access resources that are not available to less social fish (Cote, Fogarty, Weinersmith, Brodin, \& Sih, 2010). More active males (i.e., more time spent swimming and less time freezing in open spaces) provided more brood care in convict cichlids (Budaev, Zworykin, \& Mochek, 1999). Within complex environments with often competing behavioral interests (attractive and aversive stimuli), behavioral plasticity might be displayed differently and have different ecological benefits and costs than what is found under simpler laboratory settings. Certainly, these behavioral correlates have fitness consequences that have been seen in species that range from bighorn sheep, spiders, fish, lizards, and rodents (Dingemanse \& Réale, 2005; Smith \& Blumstein, 2008; Stamps \& Groothuis, 2010). Consequently, understanding the different environmental contexts, which may favor certain behavioral phenotypes over others, is an area where additional research is needed.

The distribution of animals within any singular behavioral phenotype has been found to be heavily dependent upon conditions within an ecological environment (Milinski, Lüthi, Eggler, \& Parker, 1997; Wolf \& Weissing, 2012). For example, within fish populations, the boldness expressed within a population of animals is influenced by the level of predation risk within the environment (Archard \& Braithwaite, 2011; Brydges, Colegrave, Heathcote, \& Braithwaite, 2008; Dingemanse et al., 2007; Huntingford, 1976). In addition, differences in predation risk may cause correlations in behavioral patterns that do not exist with populations under less predation risk (Bell \& Sih, 2007; Dingemanse et al., 2007). Thus, even the presence of specific phenotypes may be context and environment dependent. Thus, a connection between laboratory testing and natural conditions is needed.

A concern of field studies currently being performed is the aspect of changing environmental conditions within the lifespan of the study animal (Stamps \& Groothuis, 2010). Additionally, Stamps and Groothuis (2010) point out that any assumptions about the stability of individual personality differences in animals based on laboratory trials remain untested. Ecosystem-level interactions are highly dependent on the behavior of organisms within different niches (Schwartz et al., 2000). The expressions of these behaviors are responses to various situations that should attempt to maximize the overall fitness of an individual. Therefore, an assumption for relevance of behavioral phenotypes in nature is to display appropriate behaviors that increase survival or reproductive success. Given that environmental context influences the expression of personalities, both within and across lifetimes, the quantification and stability of animal phenotypes across environmental context seems to be a critical point (Wolf \& Weissing, 2012).

An initial solution to these concerns would be the establishment of behavioral phenotypic structures in controlled laboratory setting that are then examined in conjunction with any potential similar structures seen under real environmental conditions. The purpose of our study was to implement this solution via the examination of behavioral phenotypes within both laboratory and field settings to determine whether laboratory assays are connected to field behaviors. To test this linkage between laboratory and field behaviors, we utilized crayfish (Orconectes virilis) as a model organism. The behavioral repertoire of $O$. virilis is complex and has been well studied (Bergman \& Moore, 2003; Bergman et al., 2003; Cook \& Moore, 2008; Gherardi, 2002; Hamr, 2002). Additionally, these animals have been studied in the field under natural conditions in a variety of habitats (Bergman \& Moore, 2003; Martin \& Moore, 2007). Finally, the nervous system that underlies a number of these behaviors has been extensively studied such that environmental influences on neural activity are well known (Herberholz, Issa, \& Edwards, 2001; Yeh, Fricke, \& Edwards, 1996). We hypothesize that laboratory tests requiring similar behaviors (exploration, riskiness, and aggression) will elicit individuals that rank in similar fashion on those tests. Specifically, we expect to find similar population-wide rankings (similar individuals scoring high and another set of individuals scoring low) with behavioral tests involving anti-predator responses and exploration behaviors. We also hypothesize that individuals scoring similarly on laboratory tests will score similarly during the field test that involves similar behaviors (exploration and anti-predatory behavior).

\section{2 | METHODS}

\section{1 | Animals}

Twenty-five, reproductive form II female crayfish, O. virilis, with completely intact appendages were collected from Maple Bay (Latitude: 
45.4873, Longitude: -84.7065) on Burt Lake (Emmet County, MI, USA). Form II is the non-reproductive form for female crayfish. Crayfish were transported to the Experimental Stream Research Facility at the University of Michigan Biological Station (UMBS) in Pellston, Michigan. Only females were used in this study to eliminate possible sex differences. The carapace and chelae length were measured for all individuals (average carapace length \pm structural equation modeling [SEM]: $3.4 \pm 0.25 \mathrm{~cm}$; average chelae length \pm SEM: $3.1 \pm 0.42 \mathrm{~cm}$ ). Given this size distribution, most of these animals are between 2 and 3 years old. Typical lifespans for these animals in this area are 3 years. Crayfish were housed at the stream laboratory at UMBS in large metal troughs with continuous flow of unfiltered natural river water from the East Branch of the Maple River adjacent to the facility. All individuals were physically, but not chemically, isolated in individual plastic containers $(725 \mathrm{ml}, 36.6 \times 36.6 \times 10.1 \mathrm{~cm})$. Animals were kept under ambient temperatures depending on the natural stream water $\left(20-23^{\circ} \mathrm{C}\right)$ and a natural light/dark cycle during Jun. and Aug. of 2015. All crayfish were marked with white correctional fluid on their carapace used as a non-toxic marker that did not affect behavior to discern individuals during video recordings (Bergman \& Moore, 2004; Bergman et al., 2003). Crayfish consumed natural detritus within the stream water that fed the housing troughs.

\section{2 | Experimental protocol}

Crayfish were run through five separate laboratory behavioral assays (described below) one per day for five consecutive days. Preliminary tests demonstrated that this structure of testing produces similar results to behavioral tests that allowed recovery time between each test. Thus, to maximize the number of field tests that could be performed during the limited field season, we chose to run behavioral tests on consecutive days. Each animal was only used once in each assay. Once an individual crayfish completed all five laboratory behavioral assays, the crayfish was placed in the final field assay (described below). The order in which each crayfish ran through all the laboratory assays was randomized to prevent any order effect on the results. The individuals went through assays in a random order to also mitigate any motivational differences related to differential timing of the last protein meal. All tanks were filled with fresh stream water (same as housing troughs) daily from the Maple River adjacent to the stream laboratory facility, and each tank was rinsed before another animal went through the assay. A 15-min acclimation period was used for all assays, unless otherwise stated, and all tanks were uniformly lit from above with fluorescent lighting. All behaviors were recorded with either a DVR (SWDVR-43000H) or a camcorder (SONY Handycam HDR-CX405).

\section{3 | Exploration assays}

\subsection{1 | Arena}

To determine the exploration behavior of individuals, crayfish were placed into an arena that was designed to allow free movement of individuals. The exploration tests were performed in a $76.2 \mathrm{~cm} \times 63.5 \mathrm{~cm} \times 15.24 \mathrm{~cm}$ black Plexiglas arena, with black (a)

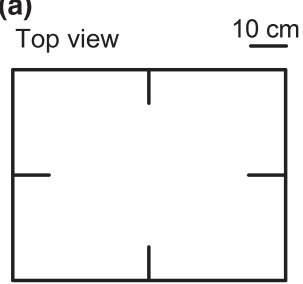

(d)

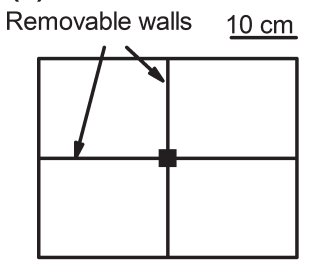

Top view (b)

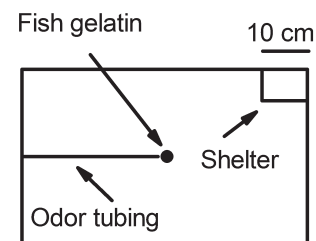

Top view

(e)

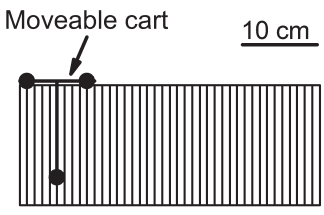

Side view (c)

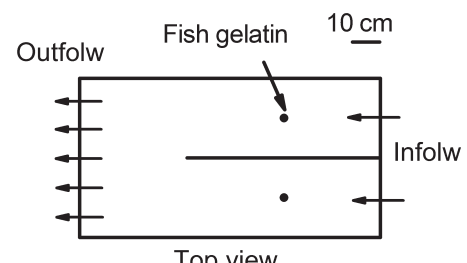

Top view

FIG URE 1 Exploration. (Top view) Four walls faced into the center of the tank. Individuals were acclimated to the center of the tank (a). Foraging with conflicting cues. (Top view) A half PVC pipe in the top right corner acted as a shelter. In the center was a container of fish gelatin acting as an attractive cue and an air stone attached to a reservoir that introduced water from a predatory bass tank acting as an aversive cue (b). Light-dark foraging. (Top view) A y-maze with food located in the center of each arm. One arm was randomly covered preventing light and acting as an unexposed area (c). Fighting arena. (Top view) The walls in the center were removable to allow separated acclimation and then lifted to allow for interaction. The drawing shows four quadrants as this tank was taken from previous social experiments where two fights occurred simultaneously. In this experiment, only half of the tank was used as only one fight was run each time (d). Tail flip initiation distance. (Side view) A moveable cart was placed along track on the top of the tank. Ping-pong balls were attached to the cart and dragged through the tank as the cart moved acting as an aversive stimulus for crayfish to perform escaping behaviors. Onecentimeter-wide black and white markings to use for distance on side wall (e) 
gravel, similar to arenas used in previous crayfish work (Basil \& Sandeman, 2000). Black substrate was glued on the bottom of the tank to create a backdrop for a movement-tracking program to better detect the animal's location (Figure 1a). The arena had four additional walls extending $10.2 \mathrm{~cm}$ into the tank at $90^{\circ}$ degree angles at the middle of the four walls, 38.1 or $31.8 \mathrm{~cm}$ from the end of the wall to add dimensionality to the arena.

\subsection{2 | Protocol}

Animals were acclimated under a $14 \times 14 \mathrm{~cm}$ square cage made from egg crating in the middle of the tank for $15 \mathrm{~min}$. After the acclimation period, the cage was lifted and the animal was allowed to explore the arena for a total of $15 \mathrm{~min}$. After $15 \mathrm{~min}$, the crayfish was then removed from the tank and the tank was rinsed with stream water to eliminate any lingering chemical cues left that may affect the assay of the next individual.

\subsection{3 | Behavioral analysis}

Ethovision Noldus XT, a motion-tracking software, was used to track a single point on the crayfish's carapace at each second in time. Previous work has shown that a single point per second is an accurate rate for movement and orientation studies (Kamran $\&$ Moore, 2015). This generated an $x, y$ coordinate arena location for the crayfish during each second of the exploration assay. An

TAB LE 1 Descriptions of the 15 behavioral measures for each of the laboratory assays analyzed in the videos listed in groups of three below. The assay number refers to the assay where the behavioral measure was used. The numbers and corresponding assay for this table are as follows: 1-TID, 2-exploration, 3-fighting, 4-foraging in different conditions, and 5-foraging with conflicting cues

\begin{tabular}{|c|c|c|}
\hline Assay & Behavioral measurements & Description \\
\hline 1 & Retreating speed & $\begin{array}{l}\text { The speed at which an individual tail flips measured by the distance travelled in the } \\
\text { first second of the tail flip, measured by the distance the animal travels during the } \\
\text { tail flip until it hits the ground after } 1 \mathrm{~s} \text {. And the average speed of the animal } \\
\text { retreating but is not retreating with a tail flip, measured by the distance the animal } \\
\text { retreated in the first } 5 \mathrm{~s} \text { divided by the distance travelled }\end{array}$ \\
\hline 1 & Reaction distance & $\begin{array}{l}\text { The distance at which an individual reacts behaviorally (increased antennae flicking, } \\
\text { backing away, change in body position) that is not a tail flip after the cart has started } \\
\text { moving. Measured from the edge of the ping-pong ball to the tip of the chelae using } \\
\text { the back wall as the reference }\end{array}$ \\
\hline 2 & Time spent touching wall & $\begin{array}{l}\text { The time at which an individual crayfish was within half of a body length from any } \\
\text { wall }\end{array}$ \\
\hline 2 & Percent tank covered & The amount of surface area of the tank the crayfish covered \\
\hline 3 & Time spent at $2-3$ & $\begin{array}{l}\text { The amount of time at which the focal animal spends at the intensity levels of } 2 \text { and } 3 \\
\text { from the ethogram }\end{array}$ \\
\hline 3 & Time spent at $4-5$ & $\begin{array}{l}\text { The amount of time at which the focal animal spends at the intensity levels of } 4 \text { and } 5 \\
\text { from the ethogram }\end{array}$ \\
\hline 3 & Time to start & $\begin{array}{l}\text { The time at which the first bout in the video begins after the wall is removed. } \\
\text { Beginning of bout is indicated by physical attack or aggressive position toward } \\
\text { opponent within one and a half body lengths of each other }\end{array}$ \\
\hline 4 & Food consumed (maze) & $\begin{array}{l}\text { The weight of the food measured in grams, which were consumed during the assay. } \\
\text { Initial mass of dish was subtracted by the ending mass of the dish }\end{array}$ \\
\hline 5 & Time spent moving toward food & $\begin{array}{l}\text { The amount of time during the assay that the animal was moving its entire body to } \\
\text { change location or rotate the body in the tank and is not in the shelter. This included } \\
\text { any time the animal location does not change but was climbing the wall }\end{array}$ \\
\hline
\end{tabular}


in-house data analysis program was written to calculate each of the behavioral measures for this section. A $35 \times 35 \mathrm{~cm}$ square grid was digitally superimposed over the exploration data, and percentage of the tank exploration was calculated by dividing the total number of grid squares entered by the crayfish by the total number of grid squares $(1,225)$. The percentage of the time (s) spent moving was calculated using a similar method to other orientation studies (Moore, Ferrante, \& Bergner, 2015). We divided the total time the crayfish spent above a minimum movement speed $(0.5 \mathrm{~cm} / \mathrm{s})$ by the total assay length. Finally, the total time (s) spent near the wall was calculated by determining when the crayfish was within half of a body length from any wall. The time a crayfish touching the wall with at least one chelae is a characteristic type of exploration by crustaceans (thigmotaxis) and is different than open exploratory behavior. A detailed description of all the behaviors across all of the assays is found in Table 1.

\section{4 | Conflicting cues assay}

\subsection{1 | Arena}

To determine the effect of predatory odor on foraging behavior, crayfish were placed into an arena that was designed to present conflicting cues (food and predatory odor). The tank was $63 \times 28 \times 14 \mathrm{~cm}$ in dimension (Figure 1b). A PVC pipe cut in half lengthwise, which is used as a shelter, was secured in one corner of the tank. In the center of the tank, an air stone connected by tubing to a reservoir was secured to the substrate. The reservoir was filled with half a liter of water from a tank (volume metal horse trough $[237.5 \times 86.4 \times 60.1 \mathrm{~cm}])$ with 27 predatory largemouth bass Micropterus salmoides. Previous work has shown that individual crayfish react to aversive odors when making decisions whether to forage and use shelters (Jurcak \& Moore, 2014). Next to the air stone, a $3 \times 3 \mathrm{~cm}$ capsule of fish gelatin served as the food stimulus. The fish gelatin was made from $46 \mathrm{~g}$ of homogenized canned sardines, $600 \mathrm{ml}$ of boiling water, and $28 \mathrm{~g}$ of Knox's unflavored gelatin (Wolf, Voigt, \& Moore, 2004). The liquid mixture was poured into separate circular $3 \times 3 \times 2 \mathrm{~cm}$ plastic bottle caps and refrigerated for $12 \mathrm{hr}$ to allow the gelatin mixture to set (Lahman, Trent, \& Moore, 2015). An overhead camera, SONY Handycam HDR-CX405, recorded the 15-min duration of the interaction. All procedures for the housing and care of the bass followed approved protocols (687097-4 [BGSU] and PRO00004591 [Michigan]).

\subsection{2 | Protocol}

The crayfish was placed in the tank under a $14 \times 14 \mathrm{~cm}$ square cage made from egg crating and was allowed to acclimate with the food and odor from bass water. For the first $8 \mathrm{~min}$ of the acclimation period, water from the predatory bass tank was introduced via the air stone. After $8 \mathrm{~min}$, the flow of water containing bass odor was stopped. Preliminary dye work showed that this was enough time for the bass odor to cover $50 \%$ of the tank, leaving the food partially covered in bass odor and the shelter free of bass water. After the acclimation period, the cage was removed and the individual had 15 min to explore the tank, eat, or hide.

\subsection{3 | Behavioral analysis}

The behaviors analyzed were time moving, time in shelter, and the weight of food consumed (Table 1). Time spent moving was defined as the duration of the assay (s) that an individual spent translating position in space as opposed to simply moving chelae and any time the animal location did not change but was climbing the wall. The time (s) in shelter was defined as the duration where the entire carapace or tail or both of an individual were covered by the PVC pipe shelter. The weight of food consumed was defined as the amount of food (g) that an individual consumed during the duration of the assay. The weight of food consumed was measured by weighing the fish gelatin before and after the assay.

\subsection{Foraging under different conditions}

\subsection{1 | Arena}

To determine the effect of exposed areas on foraging behavior, crayfish were placed into a y-maze $(112 \times 48 \times 16 \mathrm{~cm})$, with two arms $(72 \times 24 \times 16 \mathrm{~cm})$. This set up has been used in previous experiments for food choice tests (Jurcak, Gauthier, \& Moore, 2015). At one end of the $y$-maze were two openings, one in the center of the wall of each arm allowed water to flow through the $y$-maze (Figure 1c). At the other end of the $y$-maze were five $2-\mathrm{cm}$-diameter holes, $14 \mathrm{~cm}$ from the bottom on the wall opposite the opening. Each hole contained one elbow attachment and a piece of Tygon tubing that allowed for tank drainage and facilitated water flow. Two reservoirs were situated $72 \mathrm{~cm}$ above the anterior end of the $y$-maze, each attached to a piece of hosing that fed into each arm of the $y$-maze. One arm of the maze was covered with a wooden plank to darken that side of the $y$-maze while the other arm remained uncovered. The plank creates an unexposed portion of the arena. Both arms had one piece of fish gelatin (described above) placed at the center of each arm, so the only difference between arms was that one arm was exposed.

\subsection{2 | Protocol}

One arm of the maze was randomly selected via coin toss to be the dark arm and subsequently was covered with plywood. The left arm was covered 13 times, and the right arm was covered 12 times. An individual crayfish was placed into the maze at the end opposite the two arms and allowed to explore the whole arena. Qualitative personal observations showed that individuals explored the entirety of the tank during acclimation. After the acclimation period of $15 \mathrm{~min}$, the water flowed through the arena. The individual was corralled and 
TAB LE 2 Ethogram of agonistic behaviors based on level of aggression exhibited with higher numbers indicating more aggressive behaviors

\begin{tabular}{|l|l}
\hline Intensity levels & Descriptions \\
\hline-2 & $\begin{array}{c}\text { Tail flip away from the } \\
\text { opponent or fast retreat }\end{array}$ \\
\hline-1 & $\begin{array}{c}\text { Slowly back away from } \\
\text { opponent }\end{array}$ \\
\hline 1 & $\begin{array}{c}\text { Ignore opponent with no } \\
\text { response or threat display }\end{array}$ \\
\hline 2 & $\begin{array}{c}\text { Approach without a threat } \\
\text { display }\end{array}$ \\
\hline 3 & $\begin{array}{c}\text { Approach with threat display } \\
\text { using meral spread and/or } \\
\text { antennal whip } \\
\text { Initial claw use by boxing, } \\
\text { pushing, or touching with } \\
\text { closed claws }\end{array}$ \\
\hline 4 & $\begin{array}{l}\text { Active claw use by grabbing } \\
\text { opponent with open claws }\end{array}$ \\
\hline 5 & $\begin{array}{l}\text { Unrestrained fighting by } \\
\text { grasping and pulling } \\
\text { opponent's claws or } \\
\text { appendages }\end{array}$ \\
\hline
\end{tabular}

again placed at the end of the arena opposite the arms. Then, two $3 \times 3 \times 2 \mathrm{~cm}$ containers of fish gelatin as a food source were placed $36 \mathrm{~cm}$ from the end of each arm of the arena. As soon as the food was placed into the arena, the crayfish was given 15 min to consume the food.

\subsection{3 | Behavioral analysis}

The behavioral measures examined in the foraging under different light conditions were duration of time spent moving (s), duration of time spent in the lighted or uncovered arm (s), and the weight of food consumed ( $\mathrm{g}$ ) (Table 1). The total time spent in each arm was defined as the duration that an individual's entire carapace was in the arm and was moving or stationary. To calculate the total time spent in arm, the time spent in the covered arm was deducted by the time spent in the uncovered arm. The time spent moving was the duration an individual moved in the uncovered arm and non-arm section of the maze and was measured in seconds (the time spent moving did not include the covered arm because the animal was not visible). The weight of food consumed was measured by weighing the capsules with fish gelatin before and after the assay.

\section{6 | Agonistic assays}

\subsection{1 | Arena}

To determine agonistic behavior of a focal animal, crayfish were placed into an arena designed to force interactions with an opponent. To perform agonistic contests, two animals were placed into two separate quadrants of a $40 \times 40 \times 14 \mathrm{~cm}$ fight arena. Each quadrant was separated from the other by a $19-\mathrm{cm}$ removable opaque wall. The wall enabled chemical and physical isolation of the individuals before the fight assay period. This procedure is identical to others used previously with crayfish (Bergman et al., 2003; Figure 1d).

\subsection{2 | Protocol}

All focal animals were size matched with an unfamiliar opponent that was within $10 \%$ of carapace size to minimize the effect of size differences on the outcome of the fight (Cook \& Moore, 2008; Fero, Simon, Jourdie, \& Moore, 2007). Animals were placed in separate quadrants of the tank and allowed to acclimate for $15 \mathrm{~min}$. After the acclimation period, the opaque wall in the middle was removed and crayfish were allowed to interact with their opponent for $15 \mathrm{~min}$. After, animals were removed from the tank. The tank was then rinsed with stream water to eliminate any potentially lingering chemical cues. During agonistic assays, the fight was determined to begin when the individuals were within two body lengths of each other and either touching or approaching with threat displays (Table 1). The fight was determined to be over when the individuals were separated by at least two body lengths for at least $15 \mathrm{~s}$. During agonistic assays, there are multiple beginning and endings of agonistic interactions called bouts. Bouts are defined as one beginning and ending of one interaction during the assay. For purposes of this experiment, only the first bout was used in the event of multiple bouts. Within crayfish agonistic behavior, bouts after the first bout reinforce dominance status and have different temporal dynamics (Huber, Panksepp, Yue, Delago, \& Moore, 2001).

\subsection{3 | Behavioral analysis}

Fights were scored using a previously established ethogram (Table 2; Bergman et al., 2003; Bruski \& Dunham, 1987; Cook \& Moore, 2008; Fero et al., 2007). This ethogram was used to score intensity level of the fight with higher levels of intensities being more costly and thus more risky for an individual (Bergman \& Moore, 2003; Table 2). Three behavioral measures were also used to assess agonistic interactions. The time (s) to initiate the fight was defined as the time from the removal of the wall to the first interaction between individuals. Duration of time (s) the fight spent at non-escalated levels and duration of time (s) the fight spent at escalated levels were defined as the total amount of time spent at intensity levels -2 to 3 and the total amount of time spent at intensity levels $4-5$, respectively. The first interaction was defined as the focal animal approaching within two body lengths of the opponent and engaging in one of the defined agonistic behaviors (Bergman et al., 2003; Bruski \& Dunham, 1987). The duration of the fight spent at non-escalated levels was defined as the total time the two crayfish engaged in behaviors at intensity levels 2-3 (Table 1). The duration of the fight spent at escalated levels was defined as the total time that two crayfish engaged in behaviors at intensity levels 4-5 (Table 2). 


\section{7 | Tail flip initiation distance}

\subsubsection{Arena}

To determine the startle or escape behavior individual crayfish were placed into an arena that was designed to present an aversive or threatening stimulus to provoke the animal to flee. This behavioral assay has been used to test the boldness of individuals (Carter, Goldizen, \& Tromp, 2010). The arena consisted of a $15 \times 40 \times 15 \mathrm{~cm}$ $(L \times W \times H)$ Plexiglas tank. A plastic opaque track $(15 \times 40 \mathrm{~cm})$ was placed on top of the tank to allow a wooden cart to move from one side to the other. A centimeter width strip was cut through the center of the cart track to allow for the penetration of a glass rod hanging from the cart. Attached to the glass rod was a line of three ping-pong balls $(3.81 \times 3.81 \times 3.81 \mathrm{~cm})$ glued together in a horizontal array to encompass the width of the tank. A string was tied to a hook at the front of the cart and was attached to a motor that pulled the cart forward at $15 \mathrm{~cm} / \mathrm{s}$. The wall furthest from the camera was covered with 1-cm-wide vertical black and white stripes, which were used to measure motion, distance, and speed. Finally, at the far end of the tank (in relation to the ping-pong balls) was a gate that secured the crayfish at one end of the tank for acclimation (Figure 1e).

\subsection{2 | Protocol}

At the start of the assay, the tank was filled with $3.78 \mathrm{~L}$ of stream water and the track with the cart was then placed on the end of the tank farthest away from the gated area. At the beginning of the assay, a crayfish was placed into the gated section and acclimated for $2 \mathrm{~min}$. This assay is a test of startle/escape behavior; therefore, it can only interact with the aversive stimulus once. After the acclimation period, the gate was raised and the individual was allowed to move into the test area of the tank. The assay began once an individual left the gated area. At that time, the motor was activated to move the cart toward the crayfish. The assay was complete once the ping-pong ball contacted the crayfish or the crayfish tail flipped (backward fleeing motion controlled by the tail of an individual) or retreated.

\subsection{3 | Behavioral analysis}

This assay involved three separate behavioral measures to quantify the response to a threatening object. Tail flip initiation distance was defined as the distance $(\mathrm{cm})$ between the rostrum of the crayfish and the closest edge of the stimulus (ping-pong balls), when a tail flip began. Reaction distance was defined as the distance $(\mathrm{cm})$ between the closest edge of the stimulus (ping-pong balls) and the rostrum of the animal when the animal displayed a response to the stimulus (meral spread, movement backward, or freezing). Retreat speed was defined as the speed $(\mathrm{cm} / \mathrm{s}$ ) at which an individual retreated by walking or the speed of the tail flip away from the stimulus (Table 1).

\section{8 | Ecological relevance}

\subsection{1 | Field study}

Twenty-four hours after all laboratory assays were completed, an individual crayfish was placed into a field study. A crayfish was tethered to a brick via a $15 \mathrm{lb}$ test fish line tied securely to a piece of Velcro. The other half of the Velcro was securely fashioned to the back of the crayfish. In addition, the Velcro, chelae of the crayfish, and any exposed carapace were covered in white correction fluid to facilitate visualization under water. All field experiments were performed in the Maple River near the Experimental Stream Research facility at UMBS. The Maple River is a third-order boreal stream fed from the surface water of a nearby lake (Douglas Lake). The stream contains natural predators (beaver, trout, bass, and snapping turtles), detritus and other food sources, as well as native populations of Orconectes propinquus. The exact field location was the same for all crayfish and a site was located near one bank that was approximately $1.5 \mathrm{~m}$ deep. The substrate of the field location contained a mixture of sand, cobble, and large rocks that could serve as shelter. An underwater camera (Versacam remote zoom lens camera and waterproof housing; Fuhrman Diversified, Seabrook, TX, USA) was secured in the middle of a quadpod. On the top of the quadpod, red lights were mounted to supply enough light to video record behavior at night. Individual crayfish tethered on the bricks were placed underwater in the center of the set up under the camera and left for $24 \mathrm{hr}$.

\subsection{2 | Protocol}

Each individual was superglued to Velcro, which was connected to a brick by a $15-\mathrm{cm}$-long segment of fishing line. The fishing line allowed for individual movement during trial while staying within the frame of the camera. Fishing line and Velcro system have been used to tether crayfish in previous experiments, and the tether system was designed such that all appendages would remain free from entanglement. Under these conditions, crayfish exhibit similar behaviors to those animals that have not been tethered (Ludington \& Moore, 2017; Schneider \& Moore, 2000). The presence of the tether does restrict some expression of behaviors and limits the degree of freedom for movement. These limitations are necessary in order to keep the animal within the viewing field of the camera while allowing outside predators and competitors to engage the focal animal. The brick and crayfish combination was taken to the Maple River where it was placed in the center of the tripod setup with an underwater camera. The brick was placed in the center of the screen of the camera to allow for visibility of the crayfish and behaviors throughout the 24-hr period. Videos were analyzed for behavioral measures.

\subsection{3 | Behavioral analysis}

In total, there were ten behaviors that were recorded from the field assays. The ten behaviors measured digging, agonism, antagonism, predator-prey, shelter, exploration, foraging, struggle, mating, and 


\begin{tabular}{|c|c|}
\hline Behavioral measures & Description \\
\hline Exploration & $\begin{array}{l}\text { The amount of time at which the focal animal is moving its entire body } \\
\text { to change location or rotate body, is not in any shelters, and is not } \\
\text { foraging }\end{array}$ \\
\hline Agonism & The amount of time the focal animal spends fighting other crayfish \\
\hline Antagonism & $\begin{array}{l}\text { The amount of time the focal animal spends fighting other species } \\
\text { that are not crayfish }\end{array}$ \\
\hline Predator-prey & $\begin{array}{l}\text { The time during which a predator is closer than a body length (of the } \\
\text { focal animal) away from the focal animal including any physical } \\
\text { interaction the crayfish has with the predator }\end{array}$ \\
\hline Shelter & $\begin{array}{l}\text { The amount of time which the focal animal's carapace, tail, or both are } \\
\text { covered by a rock. And the time at which the crayfish is up against } \\
\text { the rock or brick and curled up with chelae close to body and not } \\
\text { moving except for rearranging the body. Time spent digging around } \\
\text { shelter to create more shelter }\end{array}$ \\
\hline Forage & $\begin{array}{l}\text { The time which the focal animal is moving or not moving but is moving } \\
\text { front two swimming legs near the front of the body, as well as } \\
\text { actually eating }\end{array}$ \\
\hline Stationary & $\begin{array}{l}\text { The time which the focal animal is not moving the entire body, and } \\
\text { legs are motionless }\end{array}$ \\
\hline Mating & $\begin{array}{l}\text { The time which the focal animal and other animal have claws locked } \\
\text { together and bodies together in mating position }\end{array}$ \\
\hline Digging & $\begin{array}{l}\text { The time in which the focal animal is using chelae or its entire body to } \\
\text { push sand, or carry it and displace sand from its original location }\end{array}$ \\
\hline Struggle & $\begin{array}{l}\text { An individual was considered struggling when it was attempting to } \\
\text { move beyond the length of the tether }\end{array}$ \\
\hline
\end{tabular}

TABLE 3 Descriptions of the behavioral measures from the field assay analyzed during the video. Each behavior seen visually during the videos is represented below stationary (Table 3). These behaviors were measured because they encompassed all activities seen while analyzing the field videos. The overall time an individual spent completing these actions over the entire 24-hr period was recorded. Descriptions of individual behaviors can be found below in Table 3 .

\section{9 | Data analysis}

\subsection{1 | Laboratory data}

A total of 25 individuals went through all five behavioral assays. In preparation for PCA and SEM, each individual laboratory behavioral response (e.g., tail flip distance, time spent moving) was divided by the largest value that was measured for the population. This procedure resulted in a proportion for each response for each of the 15 different measures. Thus, all the measures were normalized to values between zero and 1 . These proportions were loaded into an array that consisted of behavioral response on one axis of the array and individual animal on the other axis of the array.

\subsection{2 | Field data}

Similarly, each of the behavioral times for the field behaviors was normalized to the total time period of observations. Each field assay had a slight variation on the total time of observation (mean $23.6 \pm 0.2 \mathrm{hr}$ ), resulting in proportions of time each field animal spent performing specific behaviors.

\subsection{0 | Statistical analysis}

\subsection{1 | PCA}

A total of 25 crayfish were used for statistical modeling. Statistical analysis of both laboratory and field data followed procedures outlined in Dingemanse and Dochtermann (2013) and Dingemanse et al. (2007) for the PCA and multiple linear regression models. SEM, as outlined by Dingemanse, Kazem, Reale, and Wright (2010), followed these first two analyses. An initial PCA was performed for the laboratory data alone, the field data alone, and a combined data set using the laboratory measures as active variables and field data as quantitative supplementary variables. All PCAs were followed by a varimax rotation (Tabachnick \& Fidell, 2001). Individual animals appeared only once within each field or laboratory assay. The results of the PCAs were used to determine any possible a priori hypotheses of laboratory and/or field behavior. All PCAs were performed in Statistica ver. 13.2. For the PCA, the field behaviors of mating and antagonism were dropped from the analysis because only three animals exhibited mating behavior and only five animals exhibited any agonism in the field.

\subsection{2 | General multiple linear regressions}

Following the PCA, general linear multiple regression models were performed using the laboratory data to predict field behavior. Laboratory and behavioral proportions were z-transformed before 
loading into the multiple regression models to remove differences in mean variance across the different laboratory assays (Dingemanse et al., 2010). Possible models were identified using the "dredge" script in the R package "MuMIn" (Barton, 2015). Within the script, an initial "global model" was constructed for each field behavior and all 15 laboratory variables as predictors. The global model was subset to allow anywhere from zero (null model) to eight laboratory variables for prediction of field behaviors. Models were identified and ranked according to AIC, $\triangle \mathrm{AIC}, R^{2}$, and model weight. Statistical significance of the differences in the models was measured using Akaike's information criterion (AIC). AIC values were calculated from model discrepancies estimated by a maximum likelihood value using a bootstrapping method (Bollen-Stine bootstrapping with 1,000 iterations). As Dingemanse et al. (2010), significant models were determined based on the AIC of the model compared against the subsequent model using AIC values $(\triangle \mathrm{AIC})$. If these values are greater than two, this suggests less support for that combination of laboratory factors in predicting field behavior (Burnham \& Anderson, 2002). Important to note is that $\triangle \mathrm{AIC}$ values greater than two only suggest less support and do not falsify the model (Burnham $\&$ Anderson, 2002). The ranked output models were then compared to a priori hypotheses identified in the PCA. Significant models identified from the PCA and best-fit general linear multiple regressions ( $\triangle \mathrm{AIC}$ below 2 ) were then used to construct structural equation models of observed field behaviors.

\subsection{3 | Structural equation modeling}

The model results of the multiple regression models were used to create a priori hypotheses for the SEM (Dingemanse et al., 2010). Not all laboratory behaviors were considered for SEM due to nonsignificant results of PCA and regression analysis. Similarly, not all field behaviors had models with sufficient support to be included in SEM. The details for constructing and testing the SEM are found elsewhere (Dingemanse et al., 2010). Because of the large number of field behaviors (10), only structural models with significant predictive power from laboratory variables based on results in the linear regression were run. Thus, null models where no structure existed (as an a priori prediction from the multiple regressions) were not included in this analysis. As such, $R^{2}$ from the SEM was used as a measure of explanatory power of the models instead of the suggested Dx (Dingemanse et al., 2010). These $R^{2}$ can be used similarly to the $R^{2}$ from regressions in a confirmatory manner for the model (Tabachnick \& Fidell, 2001). To verify differences between models in their fits to the causal relatedness of laboratory and field behaviors, the SEMs containing different regressions used to predict identical field behavior were tested using a standard approach to compare regression coefficients (Zar, 1999). For example, one structural model could have laboratory assays 1, 2, 3, and 4 predicting field behaviors 1 and 2 , whereas a second model could have laboratory assays $2,4,5$, and 7 to predict field behaviors 1 and 2. Comparing SEM models with different regression coefficients allows the statistical validation of which laboratory assays are best predictors of similarly related field behaviors. Using a pooled standard error for each regression to create a ratio between the two models allows the construction of a $t$ value to determine significance between two models (Zar, 1999). Structural equation models were conducted using the "lavaan" R statistical package (Rosseel, 2012), and graphics of each model were constructed in semPlot using the semPaths function (Epskamp, 2014). Statistical comparisons between SEM models were performed in " $R$ " using the ANOVA function (R Core Team, 2015) and are described in terms of AIC selection criteria listed in Table 4. Each SEM was Bollen-Stine bootstrapped with 1,000 iterations.

\section{3 | RESULTS}

The normalized results from both the laboratory and field data can be found in Appendix A, and the loadings for the PCA tables can be found in Appendix B.

\section{1 | PCA results}

The results from the PCA on laboratory behaviors showed that the first two factors explained $43 \%$ of the variance in the laboratory assays (Figure $2 \mathrm{a}, \mathrm{b}$ ). The third axis provided an additional $14 \%$ of explanatory power to the correlations. Factor 1 appears to describe an axis of activity, where more negative values are associated with less goal-directed behaviors (using shelter, eating, or moving toward food) and the more positive scores correspond to goal-directed movement (retreat and fighting). Axis 2 shows almost exclusively positive values, although consumption, reaction to the tail flip device, and walking against the wall are more negative. The axis for factor 3 shows a larger spread across the axis with fighting behaviors falling out more positively (Figure $2 b$ ).

In a similar fashion, the PCA on field behaviors showed explanatory powers of $29 \%$ (axis 1), $20 \%$ (axis 2), and $17 \%$ (axis 3: Figure $2 a$ and $b$ ). Axis 1 exhibited more stationary behaviors on the positive side of the axis and moving behaviors on the negative side. Axis 2 appears to separate on goal-directed behaviors (positive values) and exploratory behaviors (negative values). Finally, axis 3 was associated with activity. Combining the field and laboratory behaviors on a single plot shows groupings of laboratory and field behaviors on the lower half of axis 2 and some disparate groups of behaviors on axes 1 and 3 (Figure $2 a$ and $b$ ).

\section{2 | GLMR results}

The results from the general linear multiple regression models (GLMR) showed significant models for several laboratory and field variables (Table 4). The results from the GLMR include the results only for single field components and those laboratory behaviors that significantly explain the field behavior. Table 4 is organized to only show top models based on the AIC criteria and models that had $\triangle$ AIC of greater than 2 are not shown (Dingemanse et al., 2010). Most 
TAB LE 4 Top multiple regression models with $\triangle$ AICc below 2. Shading denote groupings for structural equation model construction

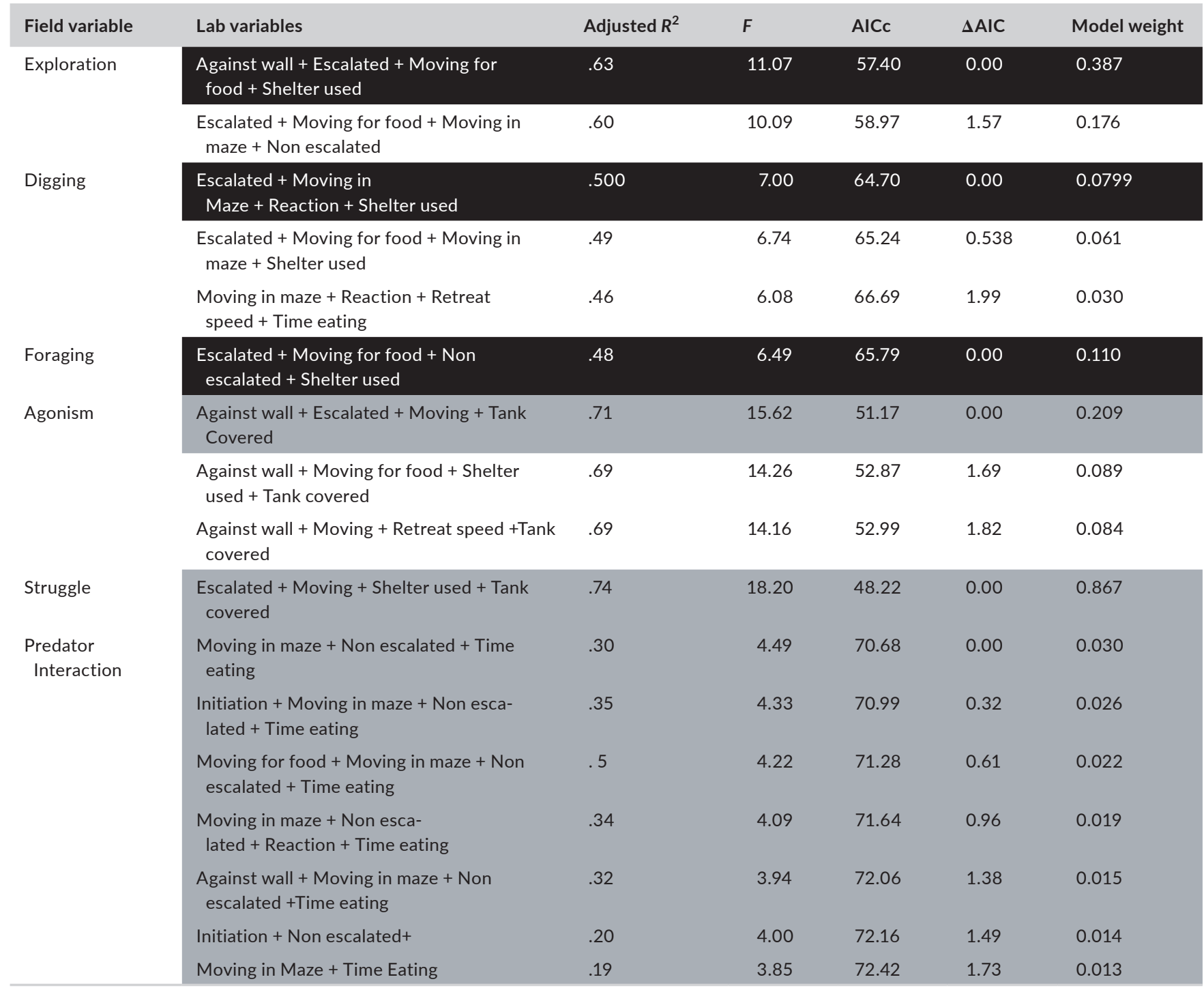

notably, the field behavior of "exploration" was significantly correlated with the laboratory behaviors of "escalated fights," "moving for food," "shelter use," and "against wall." Similarly, "digging" was significantly correlated with "moving in maze," "reaction," "shelter use," and "escalated behavior" while "foraging" in the field was correlated with "escalated fights" and "moving for food," "non-escalated behavior," and "shelter use." All other correlations are presented in Table 4. Field behaviors were subsequently grouped, based on overlapping correlated laboratory behaviors, for SEM analysis. For example, "exploration," "digging," and "foraging" were placed within one structural equation model that used "against wall," "escalated behavior," "movement for food," "shelter use," "movement in maze," "reaction," and "non-escalated behavior" as predictors. This structure is called a module and is a set of related behavioral phenotypes that is demonstrated by which laboratory behaviors explain the field behavior. Based on the output of the GLMR, two different structures were chosen for subsequent SEM modeling: fighting behavior (agonism and struggle) and searching (exploration, digging, and foraging).

\subsection{SEM modeling results}

Results from the SEM produced two different potential modules connecting the laboratory behavioral assays with the field assays (Table 5). The first potential module can be thought of as a broad structure that might include the three field behaviors, exploration-digging-foraging, which can be explained by the laboratory assays of against wall, escalated behavior, movement for food, shelter use, movement in maze, reaction, and non-escalated behavior (Table 5 and Figure 3). The second module structure connects the field behaviors of agonism-struggle with the laboratory assays of escalated behavior, against wall, shelter use, moving, and percentage of tank covered (Table 5 and Figure 4).

\section{4 | DISCUSSION}

The results from this study demonstrated three distinct findings for correlated behavioral phenotypes in the crayfish, O. virilis. First, 


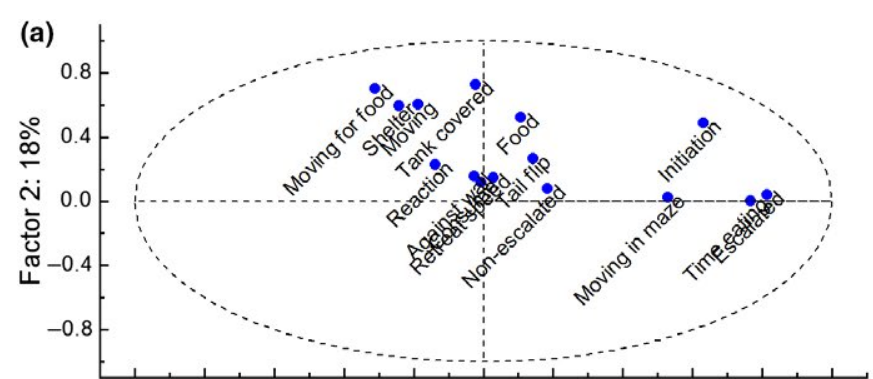

Factor 1: $24 \%$

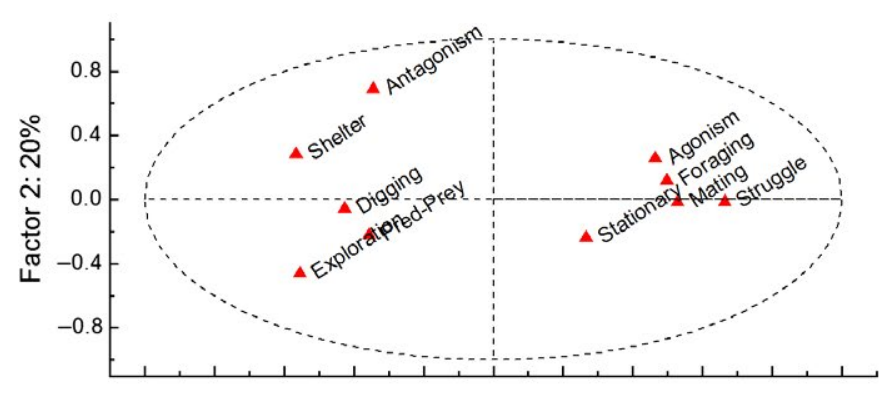

Factor 1: $29 \%$

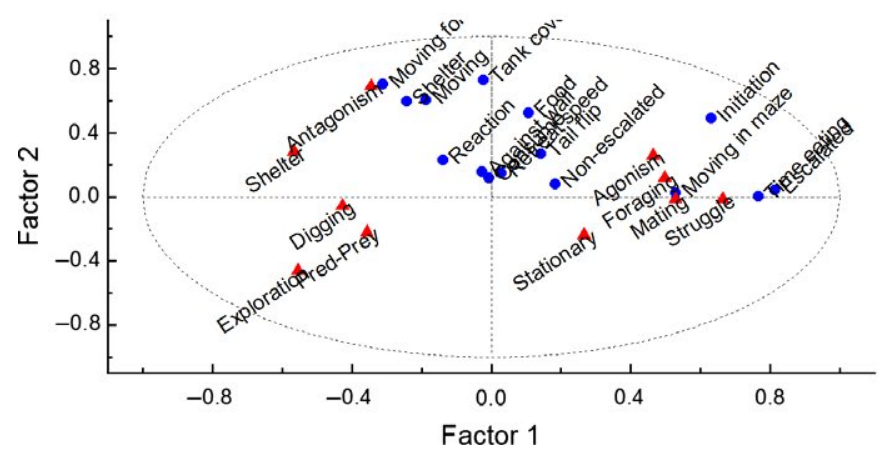

(b)

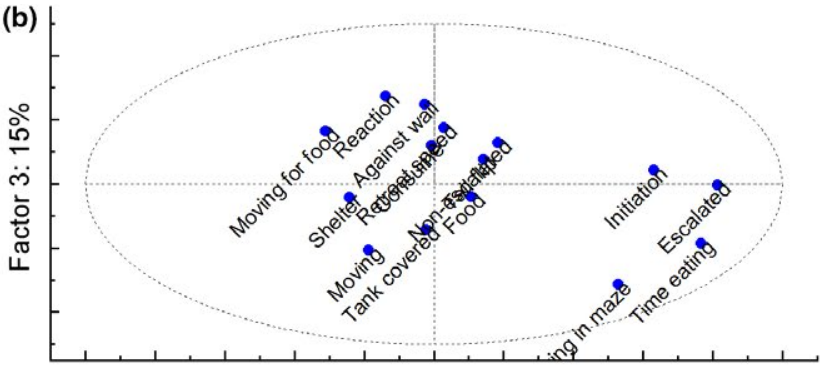

Factor 1: $24 \%$

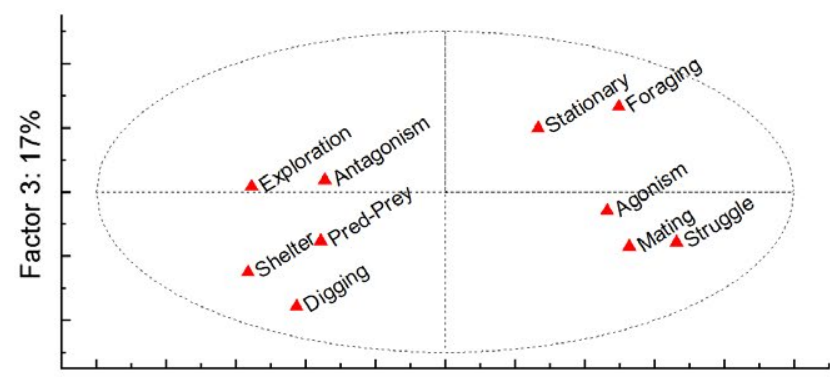

Factor 1: $29 \%$

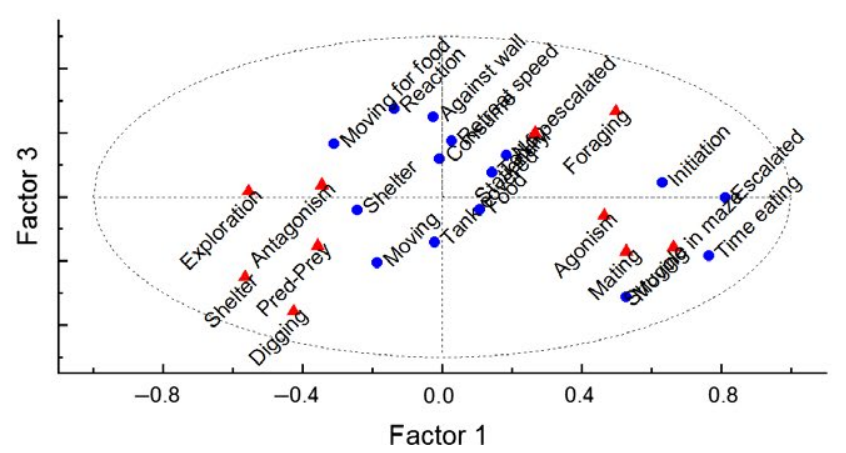

FIGURE 2 PCA for laboratory behavioral assays using normalized proportions (top row). Distribution of laboratory results with the first two axes, which explains $43 \%$ of the variation in data (a) and the first and third axes (b). The third axis explains an additional 14\%. PCA for field behavioral assays using normalized proportions (middle row). Distribution of field results with the first two axes which explains $49 \%$ of the variation in data (a) and the first and third axes (b). The third axis explains an additional 17\%. PCA for the combined laboratory behavioral assays and field behavior using normalized proportions (bottom row). [Colour figure can be viewed at wileyonlinelibrary.com]

TAB LE 5 SEM models of field behaviors using results from multiple regression models. SEM Bollen-Stine bootstrapping technique was conducted using 1,000 iterations in the R "lavaan" package. Shading denote groupings for structural equation modeling as in Table 4

\begin{tabular}{llll} 
Field variable & Field behaviour $R^{2}$ & $\begin{array}{l}\text { SEM Bootstrap } \\
p \text {-value }\end{array}$ & AIC \\
\hline Exploration-digging-foraging & $\begin{array}{l}\text { Exploration: } \\
\text {.71;Digging: .34; }\end{array}$ & .15 & 668.02 \\
& Foraging: .46 & & \\
\hline Agonism-struggle & $\begin{array}{l}\text { Agonism: .78; Struggle: } \\
.76\end{array}$ & .26 & 420.31 \\
& & & \\
\hline
\end{tabular}

correlate phenotype structures exist that can be elucidated from laboratory studies to predict behaviors in the field under more complex settings (Figures 3 and 4). This study found two different phenotype structures that explained five different field behaviors. These structures appear to correlate well with behavioral correlates described in previous work from which our definitions of modules and behavioral axes were taken (Mazué, Dechaume- Moncharmont, \& Godin, 2015; Réale, Reader, Sol, McDougall, \& Dingemanse, 2007). The first module can be defined along the established exploration-avoidance behavioral axis and coupled with the laboratory behaviors associated with movement against wall, escalated behavior, movement for food, shelter use, movement in maze, reaction, non-escalated behavior) (Figure 3 and Table 5). These behaviors together are linked with the field behaviors of exploration, digging, and foraging. As such, these behaviors are related to some aspect of a non-goal-directed movement throughout the environment. This module has been a common result across a wide array of species and conditions (Dingemanse, Both, Drent, Van Oers, \& Van 

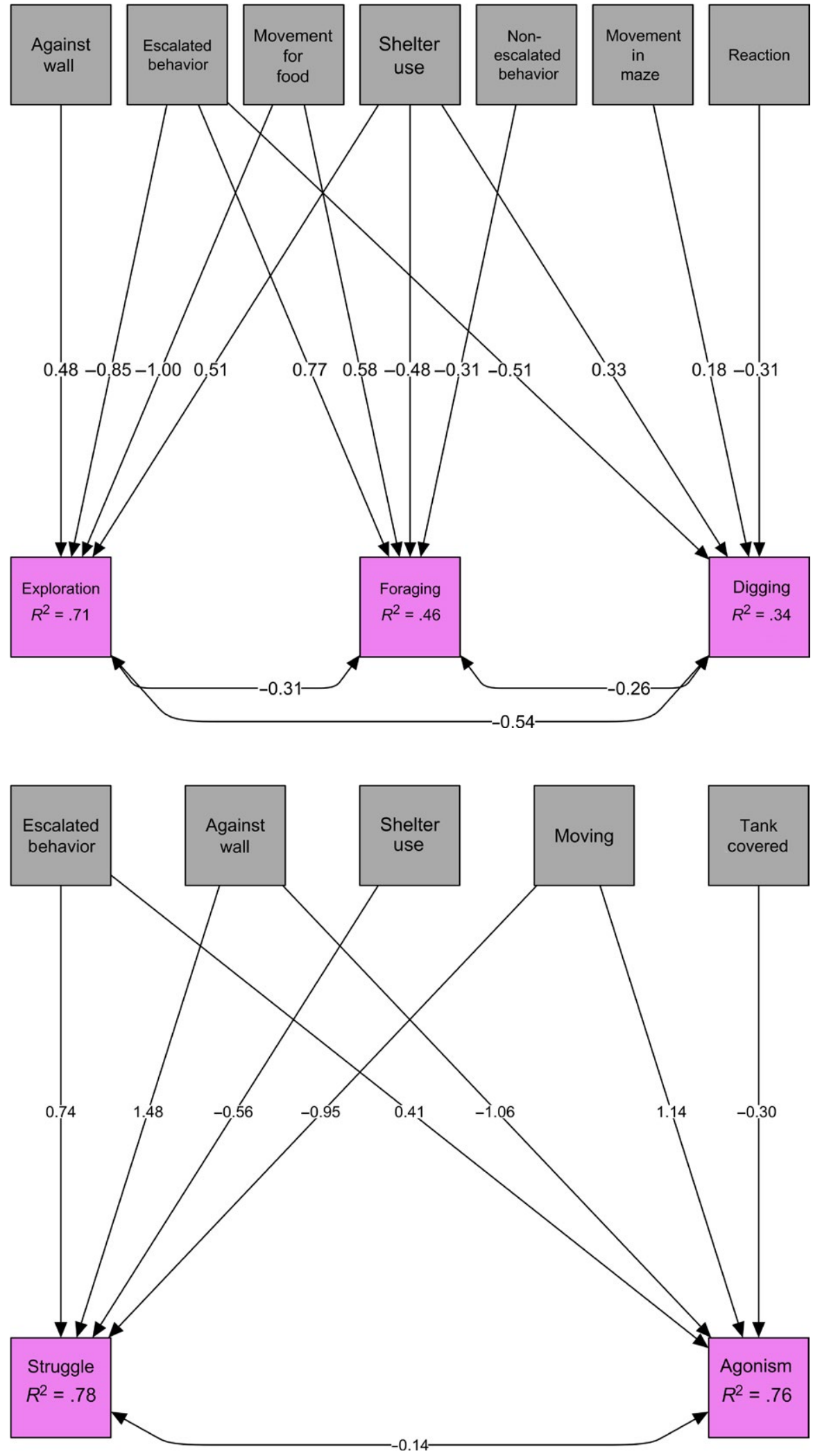

FIGURE 3 The behavioral modules found from the behavioral matrix using laboratory assays to predict field behavior for the exploration-avoidance module. The purple boxes represent field behaviors, and the gray boxes represent laboratory behaviors. The lines represent correlations between behaviors with the number representing the strength of the correlation (the higher the number the stronger the correlation), and whether the correlation is positive or negative. [Colour figure can be viewed at wileyonlinelibrary.com]
FIGURE 4 The behavioral module found in laboratory, field, and laboratory and field settings for the bold-shy module. The meaning of the different numbers is explained in legend for Figure 3. [Colour figure can be viewed at wileyonlinelibrary.com]
Noordwijk, 2002; Dingemanse, Both, Noordwijk, Rutten, \& Drent, 2003). Regarding our hypotheses, we did find some behavioral phenotypes that were correlated across the laboratory tests, but these correlations did not match our predictions for those field behaviors.
With the behavioral modules found in these studies, only the classic bold-shy continuum seemed to be correlated both in the laboratory and the field. Finally, the only correlations that were matched by our a priori predictions were the individuals with high levels of 
aggression in the laboratory also had high levels of aggression in the field.

The second module is related to the boldness-shy behavioral axis and involves a wide diversity of laboratory behaviors (escalated behavior, against wall, shelter use, moving, percent tank covered) (Figure 4 and Table 5). Together, these laboratory behaviors are predictive of the time spent in agonism or struggling found in the field behaviors. This module appears to line up with the classic bold-shy behavioral syndrome tested on many different organisms, where aggression and boldness are linked (Azevedo \& Young, 2006; Holbrook, Wright, \& Pruitt, 2014; Wilson, Coleman, Clark, \& Biederman, 1993). Certainly, aggression has been connected to boldness in different model species (Carter et al., 2010) and is used to explain behaviors observed in the laboratory to those in nature (Sneddon, 2003). Crayfish engage in agonistic contests over resources in both laboratory and field conditions (Bergman \& Moore, 2003; Bergman et al., 2003; Martin \& Moore, 2007; Wofford, Earley, \& Moore, 2015). Given the prevalence of aggressive interactions in this organism, it is not surprising to find a module that aligns laboratory assays with field aggression.

The second overall finding from these results demonstrated that some behaviors, from tests designed with specific behavioral phenotypes in mind, were correlated to each other, but unconnected to the behavior performed in complex natural situations (Figure 2). For example, the initiation of agonistic contests and time spent in non-escalated behaviors are key factors in determining the outcome of contests and hierarchy status (Moore, 2007). Yet, these behavioral factors in a laboratory setting were absent from any correlations of agonism and aggressiveness found in the field setting. In a striking contrast, several laboratory behavioral results related to foraging were completely absent from any of the structural models that predicted foraging in the field (Table 4). Prior to laboratory tests, crayfish had access to detritus albeit of smaller sizes and less variability than what was available in the field tests. In addition, the laboratory tests were run with protein-based food sources as opposed to detrital food sources. The sudden increase in detrital abundance and the change in nutritional quality in the field might explain some of these results. These results indicated that, despite the well-used design of the behavioral assays, the simplicity of the laboratory setting is not predictive of a similar behavior in the field.

Third and finally, not all of the field behavior was present in the models based on the laboratory assays despite the diversity of different laboratory designs (Figure 2 and Table 4). Three important field behaviors (shelter use, antagonism, and stationary behaviors) were absent from any of the structural equations models that were significant. Similar to the conclusions above, these field behaviors probably arise from a more complex array of sensory stimuli (sensory landscape) that, in turn, requires complex neural processing (Cronin, Johnsen, Marshall, \& Warrant, 2014; Moore \& Crimaldi, 2004). The simplicity of laboratory conditions and the lack of a realistic sensory landscape may not provide suitable range of behavioral responses that are evoked under field conditions.

\subsection{Connecting the field and laboratory assays}

A more general conclusion from this work indicated that potential behavioral correlates connect behaviors observed from laboratory assays and behaviors observed in natural field settings. Still, certain laboratory behaviors were not good predictors of any field behaviors observed. The exploration assay and contradicting cues did not correlate with any behaviors seen in the field setting, which is contrary to expectations (Stamps \& Groothuis, 2010). In addition, some field behaviors were not correlated with, or explained by any of the laboratory behaviors, such as mating, remaining stationary, and antagonism. These field variables were taken out of the analysis because a minority of the individuals exhibited these behaviors. Clearly, some of the laboratory assays elucidated phenotypes that were absent in the field, which indicated that caution should be taken in attempting to derive the presence of field-based phenotypes from purely laboratory studies.

Many current studies of behavioral phenotypes have called for the need to relate them to fitness consequences (McGlothlin, Moore, Wolf, \& Brodie, 2010; Sih et al., 2015; Smith \& Blumstein, 2008; Wolf \& Weissing, 2012). Different behavioral phenotypes have had consequences for mate selection (Godin \& Dugatkin, 1996), the survivability in predator-prey interactions (Lima \& Dill, 1990; Milinski et al., 1997), parental care (Budaev et al., 1999), and dispersal (Dingemanse \& Réale, 2005; Sih, Bell, \& Johnson, 2004a, b). Still, based on the results from this study, caution should be taken to extend some phenotypes discovered purely from laboratory studies to fitness consequences in field settings. Certainly, the contextual plasticity of laboratory sensory conditions is more simple than natural conditions (Stamps, 2016) and an approach where laboratory studies depend upon a multidimensional approach to context may be critical (Dosmann \& Mateo, 2014; Westneat et al., 2011, 2015).

Contextual plasticity could explain the existence of modules in some of the field assays. If some taxa, such as crayfish, have limited contextual plasticity, phenotypes may arise under certain ecological conditions such as a limited resource distribution or certain level of predation threat (Coleman \& Wilson, 1998; Dingemanse et al., 2007, 2010). Testing populations that inhabit environments with different levels of predation threats or even different distributions of sensory landscapes may produce a different outcome (Biro et al., 2004). Within crayfish, recent work has shown that even a simple environmental influence, such as flow (which subsequently structures olfactory signals), produces different behavioral patterns in foraging assays (Jurcak \& Moore, 2016; Moore et al., 2015). Yet, even these studies measured behavioral patterns under the limited complexity of laboratory settings.

Nervous systems can be sculpted by previous experiences even on the scale of days (Yeh, Musolf, \& Edwards, 1997; Yeh et al., 1996). Developmental plasticity and the resulting behavioral phenotype are based in the underlying neuroarchitecture and functionality of the synaptic connections as it is altered by environmental conditions. The plasticity of nervous system may be a possible mechanism that explains the existence of similar behavioral responses across 
the varied contexts seen in this study. The diverse array of sensory stimuli in space and over time (sensory landscape and those concomitant experiences) under which organisms develop could be critical in determining not only where an individual's behavior falls on a spectrum, but could also determine which behavioral phenotypes are even present within a population.

\section{5 | CONCLUSION}

This study has demonstrated that some laboratory behaviors are correlated to behaviors seen under realistic environmental conditions. In addition, some field behaviors are not explained by their laboratory counterparts and some laboratory behaviors are unconnected to behaviors elicited under natural conditions. Certainly, caution must be taken when extrapolating behavioral phenotypes from the more simplistic laboratory conditions to the complex environmental of natural field conditions.

\section{ACKNOWLEDGEMENTS}

Firstly, we would like to thank the University of Michigan's Biological Research Station for funding this project and use of their Stream Facility. Secondly, we would like to thank Bowling Green State University and members of the Laboratory for Sensory Ecology for help in data collection and reviewing this manuscript.

\section{ORCID}

Paul A. Moore iD http://orcid.org/0000-0002-4555-1178

\section{REFERENCES}

Archard, G. A., \& Braithwaite, V. A. (2011). Increased exposure to predators increases both exploration and activity level in Brachyrhaphis episcopi. Journal of Fish Biology, 78, 593-601. https://doi. org/10.1111/j.1095-8649.2010.02880.x

Azevedo, C. S., \& Young, R. J. (2006). Shyness and boldness in greater rheas Rhea americana Linnaeus (Rheiformes, Rheidae): The effects of antipredator training on the personality of the birds. Revista Brasileira de Zoologia, 23, 202-210. https://doi.org/10.1590/ S0101-81752006000100012

Barton, K. (2015). MuMIn: Multi-model inference. R package version 1.15.1. Retrieved from http:/CRAN.R-project.org/package=MuMIn

Basil, J., \& Sandeman, D. (2000). Crayfish (Cherax destructor) use tactile cues to detect and learn topographical changes in their environment. Ethology, 106, 247-259. https://doi. org/10.1046/j.1439-0310.2000.00524.x

Bell, A. M., \& Sih, A. (2007). Exposure to predation generates personality in three spined sticklebacks (Gasterosteus aculeatus). Ecology Letters, 10, 828-834. https://doi.org/10.1111/j.1461-0248.2007.01081.x

Bergman, D. A., Kozlowski, C. P., McIntyre, J. C., Huber, R., Daws, A. G., \& Moore, P. A. (2003). Temporal dynamics and communication of winner-effects in the crayfish, Orconectes rusticus. Behaviour, 140, 805-825. https://doi.org/10.1163/156853903322370689

Bergman, D. A., \& Moore, P. A. (2003). Field observations of intraspecific agonistic behavior of two crayfish species, Orconectes rusticus and
Orconectes virilis, in different habitats. Biological Bulletin, 205, 26-35. https://doi.org/10.2307/1543442

Bergman, D. A., \& Moore, P. A. (2004). Prolonged exposure to social odours alters subsequent social interactions in crayfish (Orconectes rusticus). Animal Behaviour, 70, 311-318.

Biro, P. A., Abrahams, M. V., Post, J. R., \& Parkinson, E. A. (2004). Predators select against high growth rates and risk-taking behaviour in domestic trout populations. Proceedings of the Royal Society B: Biological Sciences, 271, 2233-2237. https://doi. org/10.1098/rspb.2004.2861

Bruski, C. A., \& Dunham, D. W. (1987). The importance of vision in agonistic communication of the crayfish Orconectes rusticus. Behaviour, 103, 83-107. https://doi.org/10.1163/156853987X00288

Brydges, N. M., Colegrave, N., Heathcote, R. J., \& Braithwaite, V. A. (2008). Habitatstability and predation pressure affect temperament behaviours in populations of three-spined sticklebacks. Journal of Animal Ecology, 77, 229-235. https://doi.org/10.1111/j.1365-2656.2007.01343.x

Budaev, S. V., Zworykin, D. D., \& Mochek, A. D. (1999). Individual differences in parental care and behaviour profile in the convict cichlid: A correlation study. Animal Behaviour, 58, 195-202. https://doi. org/10.1006/anbe.1999.1124

Burnham, K. P., \& Anderson, D. R. (2002). Model selection and multimodel inferences: A practical information-theoretic approach. New York, NY: Springer-Verlag.

Carter, A. J., Goldizen, A. W., \& Tromp, S. A. (2010). Agamas exhibit behavioral syndromes: Bolder males bask and feed more but may suffer higher predation. Behavioral Ecology, 21, 655-661. https://doi. org/10.1093/beheco/arq036

Coleman, K., \& Wilson, D. S. (1998). Shyness and boldness in pumpkinseed sunfish: Individual differences are context-specific. Animal Behavior, 56, 927-936. https://doi.org/10.1006/anbe.1998.0852

Cook, M. E., \& Moore, P. A. (2008). Communication networks and loser effects interact to influence the outcome of aggressive interactions in the crayfish Orconectes rusticus. Behavior, 146, 263-281.

Cote, J., Fogarty, S., Weinersmith, K., Brodin, T., \& Sih, A. (2010). Personality traits and dispersal tendency in the invasive mosquitofish (Gambusia affinis). Proceedings of the Royal Society B: Biological Sciences, 277, 1571-1579. https://doi.org/10.1098/ rspb.2009.2128

Cronin, T. W., Johnsen, S., Marshall, J., \& Warrant, E. J. (2014). Visual ecology. Princeton, NJ: Princeton UP. Print.

Dall, S. R. X., Houston, A. I., \& McNamara, J. M. (2004). The behavioural ecology of personality: Consistent individual differences from an adaptive perspective. Ecology Letters, 7, 734-739. https://doi. org/10.1111/j.1461-0248.2004.00618.x

Dingemanse, N. J., Both, C., Drent, P. J., Van Oers, K., \& Van Noordwijk, A. J. (2002). Repeatability and heritability of exploratory behaviour in great tits from the wild. Animal Behavior, 64, 929-938. https://doi. org/10.1006/anbe.2002.2006

Dingemanse, N. J., Both, C., Noordwijk, V. A. J., Rutten, A. L., \& Drent, P. J. (2003). The relation between dominance and exploratory behavior is context-dependent in wild tits. Behavioral Ecology, 15, 1023-1030.

Dingemanse, N. J., \& Dochtermann, N. A. (2013). Quantifying individual variation in behaviour: Mixed-effect modelling approaches. Journal of AnimalEcology, 82,39-54. https://doi.org/10.1111/1365-2656.12013

Dingemanse, N. J., Kazem, A. J. N., Reale, D., \& Wright, J. (2010). Behavioural reaction norms: Animal personality meets individual plasticity. Trends in Ecology \& Evolution, 25, 81-89. https://doi. org/10.1016/j.tree.2009.07.013

Dingemanse, N. J., \& Réale, D. (2005). Natural selection and animal personality. Behaviour, 142, 1165-1190.

Dingemanse, N. J., Wright, J., Kazem, A. J. N., Thomas, D. K., Hickling, R., \& Dawnay, N. (2007). Behavioural syndromes differ predictably between 12 populations of three-spined stickleback. Animal Ecology, 76, 1128-1138. https://doi.org/10.1111/j.1365-2656.2007.01284.x 
Dosmann, A., \& Mateo, J. M. (2014). Food, sex and predators: Animal personality persists with multidimensional plasticity across complex environments. Animal Behaviour, 90, 109-116. https://doi. org/10.1016/j.anbehav.2014.01.011

Epskamp, S. (2014). semPlot: Path diagrams and visual analysis of various SEM packages' output. R package version 1.0.1. Retrieved from http:// CRAN.R-project.org/package $=$ semPlot

Fero, K., Simon, J. L., Jourdie, V., \& Moore, P. A. (2007). Consequences of social dominance on crayfish resource use. Behaviour, 144, 61-82. https://doi.org/10.1163/156853907779947418

Gherardi, F. (2002). Behavior. In D. M. Holdich (Ed.), Biology of freshwater crayfish (pp. 258-281). London, UK: Blackwell Science Ltd.

Godin, J. G., \& Dugatkin, L. A. (1996). Female mating preference for bold males in the guppy, reticulata. Proceedings of the National Academy of Sciences of the United States of America, 93, 10262-10267. https://doi. org/10.1073/pnas.93.19.10262

Gosling, S. D. (2001). From mice to men: What can we learn about personality from animal research. Psychological Bulletin, 127, 45-86. https://doi.org/10.1037/0033-2909.127.1.45

Hamr, P. (2002). Behavior. In D. M. Holdich (Ed.), Biology of freshwater crayfish (pp. 585-603). London, UK: Blackwell Science Ltd.

Herberholz, J., Issa, F. A., \& Edwards, D. H. (2001). Patterns of neural circuit activation and behavior during dominance hierarchy formation in freely behaving crayfish. The Journal of Neuroscience, 21, 2759-2767.

Holbrook, C. T., Wright, C. M., \& Pruitt, J. N. (2014). Individual differences in personality and behavioural plasticity facilitate division of labour in social spider colonies. Animal Behavior, 97, 177-183. https:// doi.org/10.1016/j.anbehav.2014.09.015

Huber, R., Panksepp, J. B., Yue, Z., Delago, A., \& Moore, P. A. (2001). Dynamic interactions of behavior and amine neurochemistry in acquisition and maintenance of social rank in crayfish. Brain, Behavior and Evolution, 57, 271-282. https://doi.org/10.1159/000047245

Huntingford, F. A. (1976). The relationship between anti-predator behaviour and aggression among conspecifics in the three-spined stickleback, Gasterosteus aculeatus. Animal Behaviour, 24, 245-260. https://doi.org/10.1016/S0003-3472(76)80034-6

Jurcak, A. M., Gauthier, S. J., \& Moore, P. A. (2015). The effects of biodiesel and crude oil on the foraging behavior of rusty crayfish, Orconectes rusticus. Archives of Environmental Contamination and Toxicology, 69, 557-565. https://doi.org/10.1007/s00244-015-0181-4

Jurcak, A. M., \& Moore, P. A. (2014). Behavioral decisions in sensory landscapes: Crayfish use chemical signals to make habitat use choices. Journal of Crustacean Biology, 34, 559-564. https://doi.org/10.1163 /1937240X-00002266

Jurcak, A. M. \& Moore, P. A. (2016). Sensory signals and the reaction space in predator-prey interactions. Hydrobiologia (In Press).

Kamran, M., \& Moore, P. A. (2015). Comparative homing behaviors of crayfish, Fallicambarus fodiens, and Orconectes rusticus. Ethology, 121, 1-10.

Lahman, S. E., Trent, K. R., \& Moore, P. A. (2015). Sublethal copper toxicity impairs chemical orientation in the crayfish, Orconectes rusticus. Animal Behavior, 113, 369-377.

Lima, S. L., \& Dill, L. M. (1990). Behavioral decisions made under the risk of predation: A review and prospectus. Canadian Journal of Zoology, 68, 619-640. https://doi.org/10.1139/z90-092

Ludington, T. S., \& Moore, P. A. (2017). The degree of impairment of foraging in crayfish (Orconectes virilis) due to insecticide exposure is dependent upon turbulence dispersion. Archives of Environmental Contamination and Toxicology, 72(2), 281-293. https://doi. org/10.1007/s00244-016-0341-1

Martin, A.L., \& Moore, P.A. (2007). Field observations of agonism in the crayfish, Orconectes rusticus: Shelter use in a natural environment. Ethology, 113, 1192-1201. https://doi.org/10.1111/j.1439-0310.2007.01429.x

Mazué, G. P. F., Dechaume- Moncharmont, F. X., \& Godin, J. G. J. (2015). Boldness- exploration behavioral syndrome: Interfamily variability and repeatability of personality traits in the young of the convict cichlid (Amatitlania siquia). Behavioral Ecology, 26, 900-908. https:// doi.org/10.1093/beheco/arv030

McGlothlin, J.W., Moore, A. J., Wolf, J. B., \& Brodie, III, E. D. (2010). Interacting phenotypes and the evolutionary process. III. Social evolution. Evolution, 64, 2558-2574. https://doi.org/10.1111/j.1558-5646.2010.01012.x

Milinski, M., Lüthi, J. H., Eggler, R., \& Parker, G. A. (1997). Cooperation under predation risk: Experiments on costs and benefits. Proceedings of the Royal Society of London B: Biological Sciences, 264, 831-837. https://doi.org/10.1098/rspb.1997.0116

Moore, P. A. (2007). Agonistic behavior in freshwater crayfish: The influence of intrinsic and extrinsic factors on aggressive behavior and dominance. In J. Emmett Duffy \& M. Thiel (Eds.), Evolutionary ecology of social and sexual systems: Crustacea as models organisms (pp. 90114). Oxford, UK: Oxford University Press. https://doi.org/10.1093/ acprof:oso/9780195179927.001.0001

Moore, P. A., \& Crimaldi, J. (2004). Odor landscapes and animal behavior: Tracking odor plumes in different physical worlds. Journal of Marine Science, 49, 55-64.

Moore, P. A., Ferrante, P. A., \& Bergner, J. L. (2015). Chemical orientation strategies of the crayfish are influenced by the hydrodynamics of their native environment. The American Midland Naturalist, 173, 17-29. https://doi.org/10.1674/0003-0031-173.1.17

R Core Team (2015). R: A language and environment for statistical computing. Vienna, Austria: R Foundation for Statistical Computing. Retrieved from http:www.R-project.org/

Réale, D., Gallant, B. Y., Leblanc, M., \& Festa-Bianchet, M. (2000). Consistency of temperament in bighorn ewes and correlates with behavior and life history. Animal Behavior, 60, 589-597. https://doi. org/10.1006/anbe.2000.1530

Réale, D., Reader, S. M., Sol, D., McDougall, P. T., \& Dingemanse, N. J. (2007). Integrating animal temperament within ecology and evolution. Biological Review, 82, 291-318. https://doi. org/10.1111/j.1469-185X.2007.00010.x

Rosseel, Y. (2012). Lavaan: An R package for structural equation modeling. Journal of Statistical Software, 48, 1-36. Retrieved from http:// www.jstatsoft.org/v48/i02/

Schneider, R. Z., \& Moore, P. A. (2000). Urine as a source of conspecific disturbance signals in the crayfish Procambarus clarkii. Journal of Experimental Biology, 203(4), 765-771.

Schwartz, M. W., Brigham, C. A., Hoeksema, J. D., Lyons, K. G., Mills, M. H., \& van Mantegem, P. J. (2000). Linking biodiversity to ecosystem function: Implications for conservation ecology. Oecologia, 122, 297-305. https://doi.org/10.1007/s004420050035

Sih, A., Bell, A., \& Johnson, J. C. (2004a). Behavioral syndromes: An integrative overview. The Quarterly Review of Biology, 79, 241-277. https://doi.org/10.1086/422893

Sih, A., Bell, A., \& Johnson, J. C. (2004b). Behavioral syndromes: An ecological overview. Trends in Ecology \& Evolution, 19, 372-378. https:// doi.org/10.1016/j.tree.2004.04.009

Sih, A., Mathot, K. J., Moirón, M., Montiglio, P. O., Wolf, M., \& Dingemanse, N. J. (2015). Animal personality and state-behaviour feedbacks: A review a guide for empiricists. Trends in Ecology \& Evolution, 30, 50-60. https://doi.org/10.1016/j.tree.2014.11.004

Smith, B. R., \& Blumstein, D. T. (2008). Fitness consequences of personality: A meta-analysis. Behavioral Ecology, 19, 448-455. https://doi. org/10.1093/beheco/arm144

Sneddon, L. U. (2003). The bold and the shy: Individual differences in rainbow trout. Journal of Fish Biology, 62, 971-975. https://doi. org/10.1046/j.1095-8649.2003.00084.x

Stamps, J. A. (2016). Individual differences in behavioural plasticities. Biological Reviews, 91, 534-567. https://doi.org/10.1111/brv.12186

Stamps, J., \& Groothuis, T. G. G. (2010). The development of animal personality: Relevance, concepts and perspectives. Biological Reviews, 85, 301-325. https://doi.org/10.1111/j.1469-185X.2009.00103.x 
Tabachnick, B. G., \& Fidell, L. S. (2001). Using multivariate statistics. Boston, MA: Allyn \& Bacon.

Westneat, D. F., Hatch, M. I., Wetzel, D. P., \& Ensminger, A. L. (2011). Individual variation in parental care reaction norms: Integration of personality and plasticity. The American Naturalist, 178(5), 652-667. https://doi.org/10.1086/662173

Westneat, D. F., Wright, J., \& Dingemanse, N. J. (2015). The biology hidden inside residual within-individual phenotypic variation. Biological Reviews, 90(3), 729-743. https://doi.org/10.1111/brv.12131

Wilson, D. S., Clark, A. B., Coleman, K., \& Dearstyne, T. (1994). Shyness and boldness in humans and other animals. Trends in Ecology \& Evolution, 9, 442-446. https://doi.org/10.1016/0169-5347(94)90134-1

Wilson, D. S., Coleman, K., Clark, A. B., \& Biederman, L. (1993). Shy-bold continuum in pumpkinseed sunfish (Lepomis gibbosus): An ecological study of a psychological trait. Journal of Comparative Psychology, 107, 250-260. https://doi.org/10.1037/0735-7036.107.3.250

Wilson, A. D., \& Stevens, E. D. (2005). Consistency in contextspecific measures of shyness and boldness in rainbow trout, Oncorhynchus mykiss. Ethology, 111(9), 849-862. https://doi. org/10.1111/j.1439-0310.2005.01110.x

Wofford, S. J., Earley, R., \& Moore, P. A. (2015). To fight or not to fight? Male and female crayfish decide differently when engaged in mixed sex interactions. Behaviour, 152, 995-1018. https://doi.org/10.1163 /1568539X-00003265
Wolf, M. C., Voigt, R., \& Moore, P. A. (2004). Spatial arrangement of odor sources modifies the temporal aspects for crayfish search strategies. Journal of Chemical Ecology, 30, 501-517. https://doi. org/10.1023/B:JOEC.0000018625.83906.95

Wolf, M., \& Weissing, F. J. (2012). Animal personalities: Consequences for ecology and evolution. Trends in Ecology \& Evolution, 27, 452-461. https://doi.org/10.1016/j.tree.2012.05.001

Yeh, S. R., Fricke, R. A., \& Edwards, D. H. (1996). The effect of social experience on serotonergic modulation of the escape circuit of crayfish. Science, 271, 366. https://doi.org/10.1126/science.271.5247.366

Yeh, S. R., Musolf, B. E., \& Edwards, D. H. (1997). Neuronal adaptations to changes in the social dominance status of crayfish. The Journal of Neuroscience, 17, 697-708.

Zar, J. H. (1999). Biostatistical analysis. Upper Saddle River, NJ: Prentice Hall.

How to cite this article: Edwards DD, Rapin KE, Moore PA. Linking phenotypic correlations from a diverse set of laboratory tests to field behaviors in the crayfish, Orconectes virilis. Ethology. 2018;124:311-330. https://doi.org/10.1111/ eth.12734

\section{APPENDIX A}

Normalized behavioral proportions from the laboratory and field studies

\begin{tabular}{|c|c|c|c|c|c|c|c|c|}
\hline ID & Moving & Against wall & Tank covered & Initiation & Non-escalted & Escalated & Tail flip & Reaction \\
\hline 18 & 0.962629 & 0.59 & 0.970874 & 0.676157 & 0.218447 & 0.004175 & 1 & 1 \\
\hline 60 & 0.737113 & 0.513333 & 0.718248 & 0.24911 & 0.174757 & 0.139875 & 0.833333 & 1 \\
\hline 80 & 0.739691 & 0.228889 & 0.522588 & 0 & 0.092233 & 0.098121 & 0.583333 & 0.681818 \\
\hline 84 & 0.463918 & 0.115556 & 0.321973 & 0.323843 & 0.048544 & 0 & 1 & 1 \\
\hline 308 & 0.698454 & 0.331111 & 0.894715 & 0.928826 & 0.237864 & 0.97286 & 1 & 0.772727 \\
\hline 342 & 0.841495 & 0.666667 & 0.728155 & 0.263345 & 0.68932 & 0.064718 & 1 & 0.318182 \\
\hline 352 & 0.76933 & 0.716667 & 0.591936 & 0.879004 & 0.184466 & 0 & 0.916667 & 0.681818 \\
\hline 371 & 0.889175 & 0.34 & 0.703481 & 0.903915 & 0.412621 & 0.544885 & 0.833333 & 0.227273 \\
\hline 454 & 0.113402 & 1 & 0.029721 & 0.953737 & 0.262136 & 0.849687 & 0.666667 & 0.5 \\
\hline 35 & 0.900773 & 0.147778 & 0.72293 & 0.153025 & 0.048544 & 0 & 0.5 & 0.227273 \\
\hline 314 & 1 & 0.59 & 1 & 0.658363 & 0.203883 & 0.004175 & 1 & 1 \\
\hline 326 & 0.751289 & 0.508889 & 0.754161 & 0.238434 & 0.174757 & 0.146138 & 1 & 0 \\
\hline 350 & 0.731959 & 0.26 & 0.548717 & 0.039146 & 0.087379 & 0.100209 & 0.916667 & 0.681818 \\
\hline 356 & 0.449742 & 0.098889 & 0.334852 & 0.316726 & 0.009709 & 0.006263 & 1 & 1 \\
\hline 462 & 0.728093 & 0.524444 & 0.672677 & 0.44484 & 0.116505 & 0.131524 & 1 & 0.954545 \\
\hline 472 & 0.684278 & 0.304444 & 0.849979 & 0.928826 & 0.237864 & 1 & 1 & 0.409091 \\
\hline 482 & 0.832474 & 0.66 & 0.706311 & 0.284698 & 0.699029 & 0.066806 & 1 & 1 \\
\hline
\end{tabular}


APPENDIX A (Continued)

\begin{tabular}{|c|c|c|c|c|c|c|c|c|}
\hline $\begin{array}{l}\text { Retreat } \\
\text { speed }\end{array}$ & $\begin{array}{l}\text { Food } \\
\text { consume }\end{array}$ & $\begin{array}{l}\text { Shelter } \\
\text { used }\end{array}$ & $\begin{array}{l}\text { Moving for } \\
\text { food }\end{array}$ & $\begin{array}{l}\text { moving in } \\
\text { maze }\end{array}$ & Consume & time eating & Exploration & Foraging \\
\hline 0.75 & 0.373563 & 0.720457 & 0.384106 & 0.928753 & 0.599754 & 0.434733 & 0.121062 & 0.02984 \\
\hline 0 & 0 & 0.057179 & 0.238411 & 0.124682 & 0.517241 & 0.120759 & 0.262373 & 0.047 \\
\hline 0.208333 & 0.821839 & 0.917408 & 0.302428 & 0.022901 & 0.533251 & 0.016101 & 0.285683 & 0.096383 \\
\hline 0.666667 & 0.436782 & 1 & 0.388521 & 0.6743 & 0.347291 & 0.905693 & 0.055089 & 0.316403 \\
\hline 0.708333 & 0.264368 & 0.236341 & 0.598234 & 0.175573 & 0.445813 & 0.055204 & 0.181997 & 0.21907 \\
\hline 0.25 & 0.695402 & 0.939009 & 0.620309 & 0.180662 & 1 & 0.218516 & 0.211178 & 0.142115 \\
\hline 0.416667 & 0.488506 & 0.038119 & 0.293598 & 0.97201 & 0.692118 & 1 & 0.072822 & 0.168223 \\
\hline 0.708333 & 0 & 0.011436 & 0.18543 & 0.508906 & 0.615764 & 0.572168 & 0.13451 & 0.366895 \\
\hline 0.125 & 0 & 0.709022 & 0.397351 & 0.908397 & 0.453202 & 0.434733 & 0.127671 & 0.031776 \\
\hline 1 & 1 & 0.841169 & 0.85872 & 0.427481 & 0.660099 & 0.232892 & 0.072926 & 0.206677 \\
\hline 1.291667 & 0 & 0.104193 & 0.242826 & 0.127226 & 0.615764 & 0.128235 & 0.25123 & 0.049732 \\
\hline 0.25 & 0.672414 & 0.917408 & 0.302428 & 0.022901 & 0.440887 & 0.010926 & 0.297903 & 0.10149 \\
\hline 1 & 0.563218 & 0.012706 & 0.443709 & 0.379135 & 0.789409 & 0.179413 & 0.067415 & 0.386083 \\
\hline 0.416667 & 0.557471 & 0.604828 & 0.783664 & 0.157761 & 0.463054 & 0.039678 & 0.11205 & 0.242909 \\
\hline 0.333333 & 0.597701 & 1 & 0.388521 & 0.666667 & 0.671182 & 0.909143 & 0.058561 & 0.333163 \\
\hline
\end{tabular}

\begin{tabular}{|c|c|c|c|c|c|c|c|}
\hline Shelter & Stationary & Mating & Digging & Agonism & Antagonism & $\begin{array}{l}\text { Predator- } \\
\text { prey }\end{array}$ & Struggle \\
\hline 0.719645 & 0.045825 & 0 & 0.078559 & 0.000174 & 0 & 0.007524 & 0.001458 \\
\hline 0.55058 & 0.128841 & 0 & 0.014134 & 0.000564 & 4.7E-05 & 0.000788 & 0.002352 \\
\hline 0.254208 & 0.315105 & 0.004811 & 0 & 0.001994 & 0 & $4.64 \mathrm{E}-05$ & 0.000962 \\
\hline 0.395407 & 0.109065 & 0 & 0 & 0.134818 & 1.17E-05 & 0.000363 & 0.000176 \\
\hline 0.497845 & 0.090598 & 0 & 0 & 0.00151 & 0 & 0.004787 & 0.000848 \\
\hline 0.589348 & 0.073338 & 0 & 0.043624 & 0.002418 & 0.000349 & 0.000199 & 0.002181 \\
\hline 0.30461 & 0.228163 & 0.190814 & 0.003089 & 0.000606 & 0 & 0.000595 & 0.04094 \\
\hline 0.341981 & 0.178979 & 0 & 0 & 0.001802 & 0 & 0.000249 & 0.002359 \\
\hline 0.707406 & 0.044576 & 0 & 0.082846 & 0.000178 & 0 & 0.002904 & 0.001553 \\
\hline 0.668923 & 0.071599 & 0 & 0.000213 & 0.001162 & 0.000486 & 7.11E-05 & 0.000367 \\
\hline 0.582698 & 0.133751 & 0 & 0.014957 & 0.000545 & $4.74 \mathrm{E}-05$ & 0.003698 & 0.002252 \\
\hline
\end{tabular}


APPENDIX A (Continued)

\begin{tabular}{llllllll} 
Shelter & Stationary & Mating & Digging & Agonism & Antagonism & $\begin{array}{l}\text { Predator- } \\
\text { prey }\end{array}$ & Struggle \\
\hline 0.252095 & 0.315705 & 0.005156 & 0 & 0.002074 & 0 & 0.004373 & 0.001007 \\
\hline 0.440899 & 0.097745 & 0 & 0.00192 & 0.004528 & $7.11 \mathrm{E}-05$ & 0.000972 & 0.000142 \\
\hline 0.466441 & 0.049969 & 0.102568 & 0.004184 & 0.00448 & 0 & 0.000723 & 0.000924 \\
\hline 0.380323 & 0.104903 & 0 & 0 & 0.139227 & 0 & 0.000356 & 0.000178 \\
\hline 0.482477 & 0.090574 & 0 & 0 & 0.001541 & 0 & 0.000415 & 0.000865 \\
\hline 0.588435 & 0.071824 & 0 & 0.041482 & 0.002228 & 0.000344 & 0.000178 & 0.002086 \\
\hline 0.309708 & 0.229659 & 0.192064 & 0.003224 & 0.000604 & 0 & 0.001031 & 0.040368 \\
\hline 0.198097 & 0.256966 & 0 & 0.000296 & 0.000853 & 0 & $3.56 \mathrm{E}-05$ & 0.015621 \\
\hline
\end{tabular}

\section{APPENDIX B}

PCA loadings used for the structural equation modeling

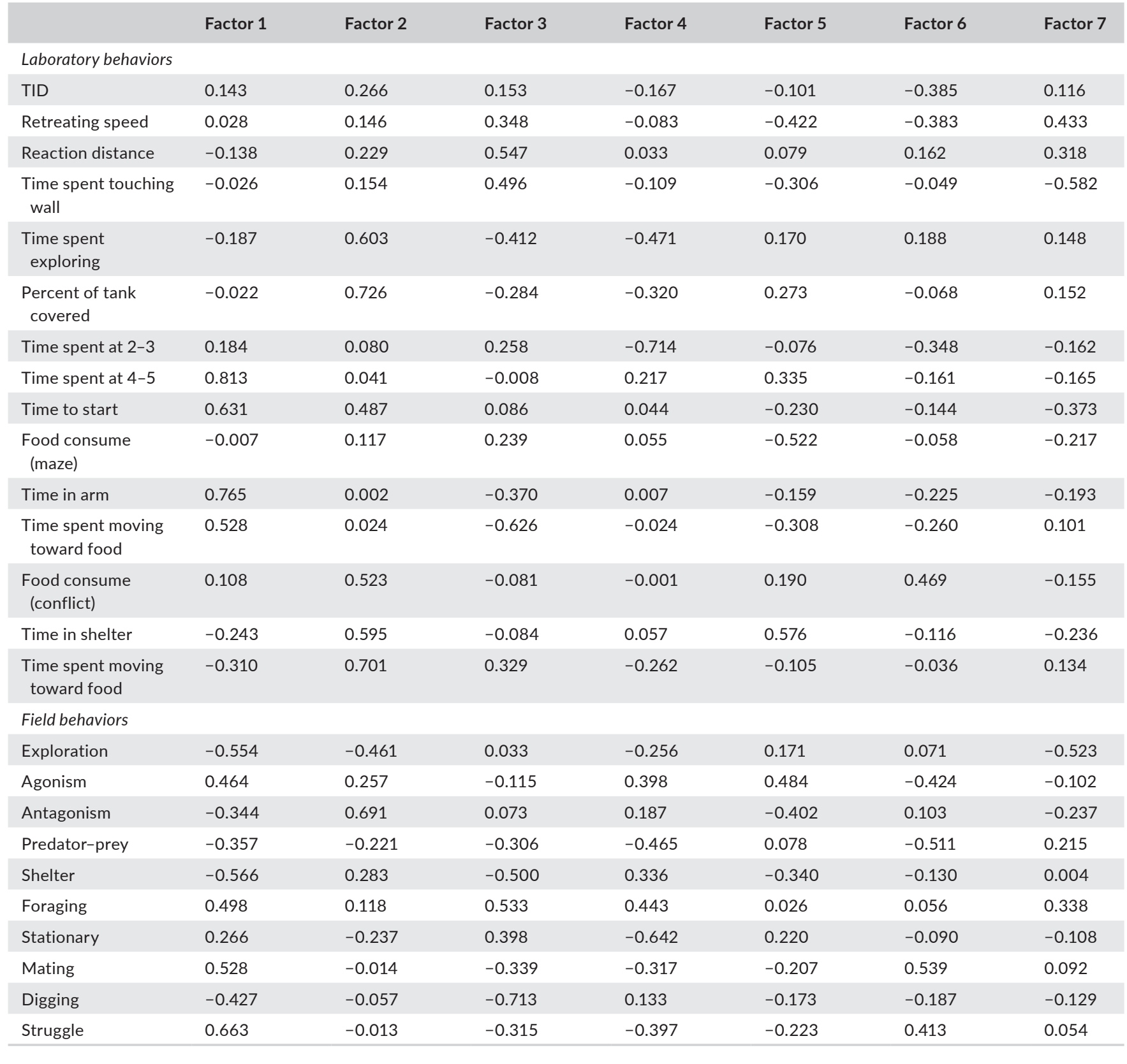


APPENDIX B (Continued)

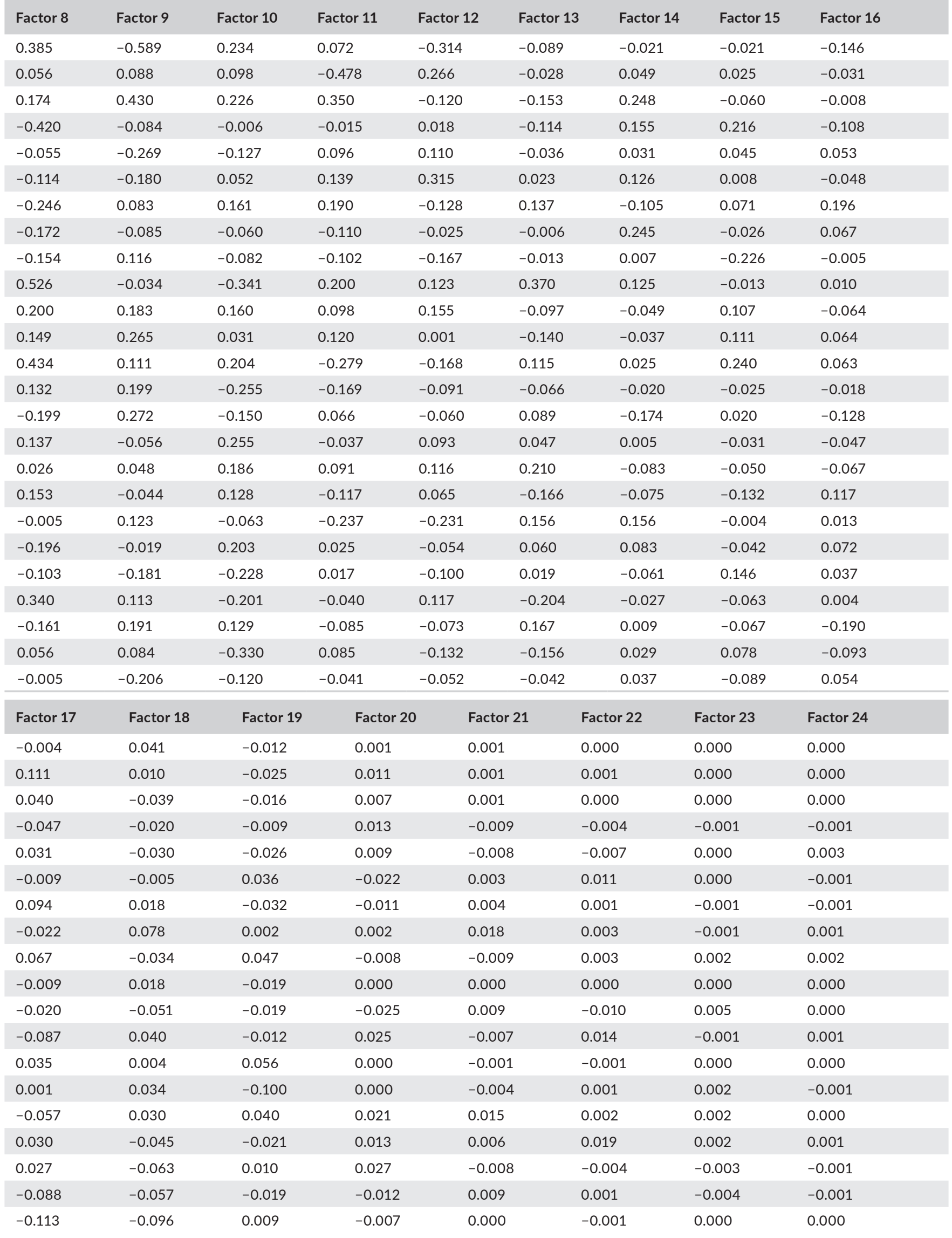


APPENDIX B (Continued)

\begin{tabular}{lllllllll} 
Factor 17 & Factor 18 & Factor 19 & Factor 20 & Factor 21 & Factor 22 & Factor 23 & Factor 24 \\
\hline 0.008 & 0.057 & 0.014 & -0.002 & -0.014 & 0.003 & 0.004 & -0.002 \\
0.001 & -0.081 & -0.021 & -0.016 & -0.005 & 0.016 & 0.001 & -0.001 \\
\hline-0.018 & 0.032 & 0.050 & -0.009 & -0.014 & 0.002 & -0.001 & -0.002 \\
\hline-0.007 & 0.025 & -0.049 & -0.020 & -0.005 & 0.004 & -0.003 & 0.000 \\
\hline 0.148 & -0.028 & 0.021 & -0.006 & 0.008 & 0.003 & -0.003 & -0.001 \\
\hline 0.022 & -0.059 & -0.009 & 0.038 & 0.006 & -0.001 & 0.002 & -0.003 \\
\hline
\end{tabular}

